\title{
Development of communicative skills of preschool children in cognitive activity
}

\author{
I.G. Kalinina ${ }^{1 *}$, I.V. Enova ${ }^{2}$, and N.M. Tolkova ${ }^{3}$ \\ ${ }^{1}$ State Educational Institution of Higher Education of the Moscow Region State Humanitarian and \\ Technological University of Orekhovo-Zuevo, Orekhovo-Zuevo, Russia \\ ${ }^{2}$ State Educational Institution of Higher Education of the Moscow Region State Humanitarian and \\ Technological University of Orekhovo-Zuevo, Orekhovo-Zuevo, Russia \\ ${ }^{3}$ State Educational Institution of Higher Education of the Moscow Region State Humanitarian and \\ Technological University of Orekhovo-Zuevo, Orekhovo-Zuevo, Russia
}

\begin{abstract}
The intensification of the development of society leads to significant changes in the education system. With the release of normative documents in preschool education, global changes have taken place aimed at developing technologies for the communicative development of children in various types of activities. The emphasis is on the development of universal educational skills, through the ability to independently find the necessary information using a variety of technologies and communication with peers and adults. The communicative development of preschool children is of great importance and is a strategic direction of Russian education. In the course of the study, theoretical (annotation, theoretical analysis, pedagogical modeling) and empirical research methods (studying the products of children's activities, studying preschool documentation, observation) were used. The types of children's activities aimed at the allround development of the child have been determined. The communicative skills of a preschool child are systematized, the main features of the cognitive development of preschoolers are highlighted. The result of the study was the substantiation of the effectiveness of the use of lessons on cognitive activity on the development of communication skills of preschool children. Realizing the direction of the development of communication skills of preschool children through the use of cognitive activity, it is important to clearly think over the educational potential of a preschool organization.
\end{abstract}

\section{A problem statement}

In modern society, serious changes are taking place in various areas, including in the education system. With the release of normative documents (Federal Law "On Education in the Russian Federation", Federal State Educational Standard of preschool education, etc.), global changes have taken place in preschool education aimed at developing technologies for the communicative development of children in various activities. The emphasis of the

\footnotetext{
*Corresponding author: prof-ped.gpa@mail.ru
} 
Federal State Standard is made on the development of universal educational skills, through the ability to independently find the necessary information using a variety of technologies and communication with peers and adults. Communication of people, that is, interaction through communication, plays an important role in the development of personality, which begins at birth and continues throughout life. The problem of communicative interaction of preschoolers with adults and peers is an urgent task of education. The communicative development of children plays an important role and is a strategic direction of Russian education.

\subsection{The objective of the work}

In the course of the study, theoretical (annotation, theoretical analysis, pedagogical modeling) and empirical research methods (studying the products of children's activities, studying preschool documentation, observation) were used.

The study of the problem of communication and communication is developed in the works of A.A. Bodalev, L.S. Vygotsky, P.P. Terekhov, A.V. Ukhanova, L.A. Dubina, A.N. Leontiev, G.M. Andreeva, N.V. Klyueva, Yu.V. Kasatkina, E.E. Kravtsova, and others [1$6]$.

The works of A.V. Mudrik, V. A. Slastenin, E. Durkheim, G. Gidings, C. Cooley, and others are devoted to theoretical studies of the socialization of children [7].

The practical orientation to the socialization of preschool children is justified in the studies of G.P. Novikova, A.K. Markova, N.F. Gubanova, A.A. Mayer, T.V. Timokhina, N.M. Tolkova, and others $[8,9]$.

Coverage of theoretical issues of communication of preschool children is found in the research of M.I. Lisina, T.A. Repina, E.O. Smirnova, D.B. Elkonin, etc. [10-13].

A huge role in understanding the importance of the problem under study is played by scientific approaches: activity, research, and system (A.N. Leontiev, L.S. Vygotsky, N.E. Veraksa, A.N. Poddyakov, I.V. Blauberg, V.N. Sadovsky, etc.) [1, 5].

A. Disterweg, E.H. Erikson, K. Jung, L.V. Zankov, I.P. Podlasy, and others were engaged in the study of the cognitive development of children. A.A. Rean, V.S. Rottenberg, S.L. Rubinstein, V.A. Slastenin, D.E. Berline, Yu.S. Yurkevich, L.I. Badanina, L.N. Prokhorova, T.I. Shamova, K.M. Ramonova, etc. were engaged in the development of cognitive activity. Questions of cognitive development of children are dealt with by domestic and foreign teachers and psychologists. L.I. Bozhovich, V.N. Myasishchev, S.L. Rubinstein, and others made a great contribution to the study of the problem of development and formation of the foundations of cognitive development in children. [1420].

In the studies of A.V. Zaporozhets, M.I. Lisina, A.G. Ruzskaya, Z.M. Boguslavskaya, D.B. Elkonin, it is noted that communication skills and abilities help the child's mental development, and affect the overall level of his activity [11, 21, 22].

At the stage of a child's transition to school, the role of communicative skills comes to the fore (EE Shuleshko, GG Kravtsov, VA Petrovsky, etc.). The development of communication skills is an important stage in ensuring the continuity of preschool and primary education, a fundamental condition for successful learning activities.

Researchers G.M. Andreeva, N.V. Kuzmina consider the concept of "communicativeness" as the ability to communicate. In addition, G.M. Andreeva considers communicative skills as a set of actions, the basis of which is a person whose activity is aimed at the realization, reflection and transformation of reality.

Thus, the communicative competence in the research of modern teachers and psychologists is considered as the main direction of the preschooler's personality 
development, aimed at well-being in social and intellectual development, in the development of specifically children's activities.

\section{Results of the research}

Communicative - cognitive development takes a significant place in the formation of a child's personality. Learning the world around him, the preschooler gets personal ideas about objects and phenomena of the surrounding world [23]. Children's development unfolds in several interrelated directions: social and communicative, cognitive, speech, artistic and aesthetic, physical.

Tasks of the development of a preschool child in accordance with the Federal State Standard of Preschool Education:

- assimilation of moral, ethical, generally accepted norms and rules of society;

- development of communication;

- development of independence;

- the formation of emotional intelligence;

- instilling the basics of safe behavior in society, etc.

The implementation of tasks is carried out in all types of children's activities.

The implementation of the above tasks in the development of preschool children is aimed at gaining personal experience of each child in various types of activities (Table 1).

Table 1. Types of children's activities

\begin{tabular}{|c|c|c|}
\hline \multicolumn{2}{|r|}{ Kind of children's activity } & \multirow[b]{2}{*}{$\begin{array}{l}\text { Aimed at development: } \\
\text { - self-confidence; } \\
\text { - the formation and development of mental } \\
\text { processes; } \\
\text { - development of imagination; } \\
\text { - the ability to transfer the functions of one } \\
\text { object to another (substitution principle); } \\
\text { - getting the result of the activity; }\end{array}$} \\
\hline 1. & Play activity & \\
\hline 2. & Research activities & $\begin{array}{l}\text { - cognitive activity; } \\
\text { - independent decision making; } \\
\text { - striving to transform the surrounding world } \\
\text { according to the laws of scientific research; }\end{array}$ \\
\hline 3. & Visual activity & $\begin{array}{l}\text { - the formation of a personal aesthetic attitude to } \\
\text { the surrounding world; } \\
\text { - the formation of elementary ideas about the } \\
\text { types of contemporary art; } \\
\text { - independent creative activity; }\end{array}$ \\
\hline 4. & Subject activity & $\begin{array}{l}\text { - the personality of the child through cognition of } \\
\text { the surrounding (objective) and social world; }\end{array}$ \\
\hline 5. & Cognitive activity & $\begin{array}{l}\text { - curiosity; } \\
\text { - the interests of the preschooler (knowledge of } \\
\text { the interests of the preschooler); } \\
\text { - deliberate activity; }\end{array}$ \\
\hline 6. & Communicative activity & $\begin{array}{l}\text { - communication; } \\
\text { - interaction with peers and adults; } \\
\text { - independence; } \\
\text { - purposefulness. }\end{array}$ \\
\hline 7. & Constructive activity & $\begin{array}{l}\text { - mental abilities; } \\
\text { - labor activity; } \\
\text { - the ability to achieve the set goal; }\end{array}$ \\
\hline 8. & Project activities & $\begin{array}{l}\text { - independence; } \\
\text { - creativity. }\end{array}$ \\
\hline
\end{tabular}


The above activities make a great contribution to the process of communicative development of preschoolers.

Our team analyzed the problems in the formation of the communication skills of a modern preschool child, we identified the key contradictions:

1. On the one hand, despite the rapid development of the surrounding world, the preschooler continues to play, the content of play activity has changed, and preschoolers prefer computer games to games with their peers. On the other hand, with a methodically well-organized developing subject-spatial environment, digital educational resources contain enormous potential for the development of preschoolers. A contradiction arises between the cognitive interest of children in new educational technologies and the unwillingness of teachers and parents to create a developing subject-spatial environment that satisfies the cognitive needs of children.

2. The second contradiction is associated with the format of the organization of classes. It lies in the natural curiosity of preschoolers, the desire to master new types of creative and experimental activity, and the uniformity of forms of organizing direct educational activities.

3. The third contradiction is associated with the manifestation of a positive-emotional attitude to communication among preschoolers, and the emotional closeness of adults.

The resolution of these contradictions will create favorable psychological and pedagogical conditions for the formation of the communicative skills of preschoolers in cognitive activity.

Problems in the development of a harmonious personality in preschool age are of a twosided nature: on the one hand, it is the unwillingness of the family to create conditions for the successful development and socialization of the child, on the other hand, it is the weakening of the ties between the family and the preschool organization [23, 24].

Communication with peers and adults is one of the main human needs and is an important condition for personality development. Only by interacting with others can a person be able to socialize in society, find his niche in society. Communicative activity becomes basic, this is due to the fact that communication is associated with all types of human activity and contributes to their successful implementation [25].

What is communication? Communication - from lat. "Communication" message, transmission, from "communicare" - to talk, transmit, report. A specific form of interaction between people, carried out using verbal and non-verbal means and methods.

Communication skills that a preschool child should have:

1. Possession of means and forms of communication with peers and adults.

2. Use of verbal communication.

3. Using non-verbal communication.

4. Own constructive ways of interaction (negotiate, exchange items, assign roles).

5. Change communication style, depending on the situation.

The activity of a preschool child is based on activity, and cognitive activity plays an important role in the development of a preschooler. In studies devoted to the cognitive activity of children (D.B. Bogoyavlenskaya, A.V. Petrovsky, G.I.Shchukina, etc.), it is noted that cognitive activity is one of the paramount qualities necessary for the full mental development of a child, as well as the authors regard it as a stimulus in the development of interest in the knowledge of the surrounding processes and phenomena.

For the correct implementation of the full-fledged cognitive development of preschool children, it is necessary that the activity be carried out in the main blocks of educational activity:

1. Cognitive activities (specially organized).

2. Joint and independent cognitive activity.

3. Independent cognitive activity. 
Organized cognitive activity in a preschool organization helps children independently obtain information about objects and phenomena, and the teacher can create conditions for the most effective learning.

The entire research program was aimed at identifying and organizing the psychological and pedagogical conditions of the communicative skills of preschool children in cognitive activity in order to obtain more reliable data. In this connection, a quasi-experiment was carried out.

The purpose of the quasi-experiment: to identify and create in the educational space the necessary psychological and pedagogical conditions for the formation of communicative skills through cognitive activity.

Quasi-experiment tasks:

1. To reveal the characteristic features of cognitive activity aimed at the formation of communicative skills.

2. Identify the level of development of communication activities.

3. Develop the ability to interact in a children's team.

The research was carried out in several stages. At the first stage, a series of developmental lessons was developed aimed at the implementation of the intended goals and objectives of the study, diagnostic material was selected for the study of the communication skills of preschoolers, and the practical material of preschool organizations in the Moscow region was systematized.

The study was conducted on the basis of several kindergartens: the municipal preschool educational institution Kindergarten No. 53 d. Kabanovo of the Orekhovo-Zuevo urban district, the municipal budgetary preschool educational institution "Kindergarten No. 28" of the Shatura city district, the municipal preschool educational institution Child Development Center, kindergarten No. 12 of the city district Orekhovo-Zuevo.

The package of techniques used by us at the stage of diagnosing the communicative skills of preschool children included:

1. "Diagnostics of the development of communication with peers" I.A. Orlova, V.M. Kholmogorova;

2. "A map of observations of the manifestation of communicative abilities in preschool children" Shchetinina, M.A. Nikiforova.

3. "Diagnostics of children's abilities for partner dialogue" A.M. Shchetinina.

Diagnostics of the development of communication with peers made it possible to reveal that $60 \%$ of the respondents had an average level of communication (parameter indicators have an average value - interest, initiative, sensitivity, prosocial actions, means of communication, active speech). $25 \%$ have a high level of communication and $15 \%$ have a low level (weak manifestation of all parameters) (Diagram 1).

Communication with peers

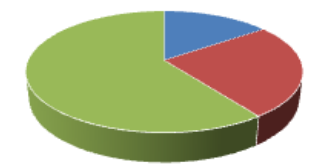

- Low communication level = Average communication level

" High level of communication "

Diagram 1. Communication with peers. 
Thus, only $25 \%$ of the respondents have high-level communication skills with peers, while the rest of the children have average and low levels, which indicates an insufficient formation of communication skills.

A map of observations of the manifestation of communicative abilities in preschool children "AM Shchetinina, MA Nikiforova. made it possible to identify the level of communication skills among preschoolers. The diagnostic results showed that the low level in $20 \%$ of children, $40 \%$ was the average level, $40 \%$ was the high level, and a very high level was not detected (Diagram 2).

\section{Communication skills of preschoolers}

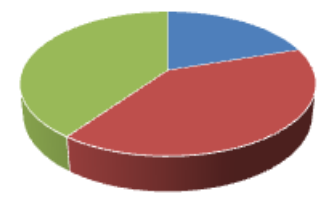

- Low level " Average level " High level " Very high level

Diagram 2. Communication skills of preschoolers

Thus, this technique made it possible to reveal that the majority of the subjects have medium and low communication skills. There is no very high level.

When carrying out the "Diagnostics of children's abilities for partner dialogue" by AM Shchetinina, we found that $1 \%$ of children had a zero level of ability for partner dialogue, $18 \%$ had a low level, $50 \%$ had an average level, and only $31 \%$ of subjects had a high level of ability to partner dialogue (Diagram 3).

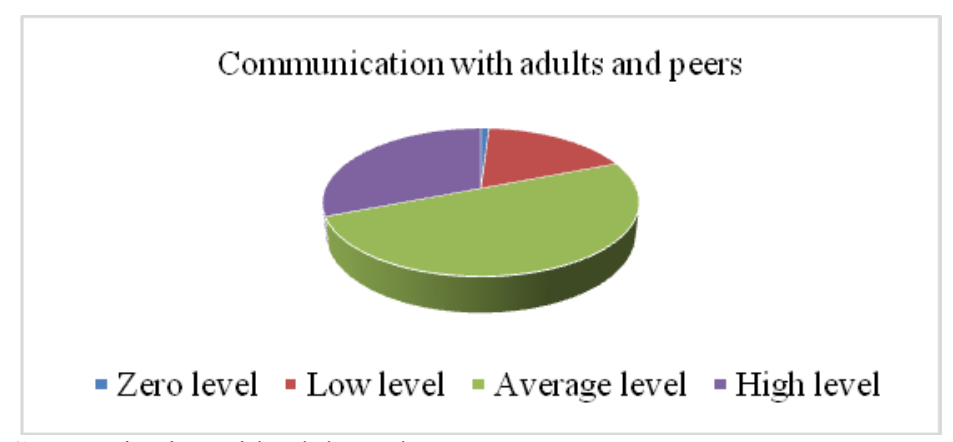

Diagram 3. Communication with adults and peers

This technique made it possible to identify the level of abilities for partner dialogue in more than half of the children at the middle level.

All activities were built taking into account the goals, the task of the study. The study group included 86 children of seven years old. The research took place during the academic year. The work was carried out in group and subgroup forms.

In order to determine the effectiveness of activities aimed at developing communication skills through cognitive activity, a quasi-experiment was carried out.

At the stage of the control section, the same diagnostic methods were used as at the diagnostic stage ("Diagnostics of the development of communication with peers", "Map of observations of the manifestation of communicative abilities in preschool children", "Diagnostics of children's abilities for partner dialogue"). At the above stage, significant positive changes in the communicative development of the subjects were revealed. 
We carried out a comparative analysis of the results, on the basis of which a conclusion was made about the effectiveness of specially designed lessons on cognitive activity, their systematic introduction into the educational process made it possible to increase the formation of communicative skills in the subjects.

\section{Conclusions}

At the Pedagogical Faculty of the State Educational Institution of Higher Education of the Moscow Region "State Humanitarian and Technological University". The teaching staff concluded that the study made it possible to study the specifics of the development of communicative skills through cognitive activities in a preschool educational organization.

The discussion resulted in the following conclusions:

1. The introduction of specially organized developmental classes in cognitive activity leads to the intensive development of the communication skills of preschoolers.

2. The development of communicative skills of preschool children through the use of cognitive activity in preschool education can be represented as a model that provides interaction with all participants in the educational process and aimed at the systemic formation of elements of communicative competence in preschoolers.

3. To implement the model, it is necessary to create psychological and pedagogical conditions for the formation and development of the communicative skills of preschool children in cognitive activity:

- creation of an enriched developmental subject-spatial environment, contributing to the formation of motivation and cognitive interest in preschoolers, and, as a consequence, the development of communicative activity;

- the inclusion of various forms of pedagogical interaction (entertaining classes, experimentation, the creation of digital educational resources of a cognitive orientation, the creation of creative products and problem-search situations in direct educational activities, the integration of various educational areas);

- stimulating the manifestation of a positive-emotional attitude to communication among all participants in the educational process.

The activities of a modern kindergarten are aimed at the all-round development of a preschool child. Realizing the direction of the development of communication skills of preschool children through the use of cognitive activity, it is important to clearly think over the educational potential of a preschool organization. In addition, it is important to take into account human resources, this is due to the fact that only a qualified, creative teacher is capable of implementing innovative educational programs for preschool education.

\section{References}

1. L.S. Vygotsky, Child development psychology, 512 (2003)

2. L.A. Dubina, Communicative competence of preschoolers: a collection of games and exercises, 64 (2006)

3. N.V. Klyueva, Yu.V. Kasatkina, We teach children to communicate. A popular guide for parents and educators, 237 (1996)

4. E.E. Kravtsova, A child within communication: how preschool children communicate with each other, Preschool education, 4, 6 (2005)

5. A.A. Leont'ev, Pedagogical communication, 47 (2009)

6. A.V. Ukhanova, Development of emotions and communication skills in a child, 128 (2011) 
7. C.C. Lemert, Social Theory: The Multicultural and Classic Readings, 50 (2010)

8. I.G. Kalinina, N.M. Tolkova, T.V. Timokhina, Specificity of the formation of elementary mathematical concepts in preschool children in inclusive groups, Prospects for Science and Education, 4(40), 351-360 (2019)

9. N.M. Tolkova, The relationship between the specifics of communication and the age characteristics of young children, Bulletin of the Vladimir State University named after Alexander Grigorievich and Nikolai Grigorievich Stoletovs, 22(41), 129-136 (2015)

10. L.N. Glazunova, E.O. Smirnova, The stages of communication: from one to seven years, Education, 143 (1992)

11. M.I. Lisina, Communication, personality and psyche of a child, 384 (2007)

12. E.O. Smirnova, V.M. Kholmogorova, Interpersonal relations of preschoolers: diagnostics, problems, correction, 158 (2003)

13. D.B. Elkonin, Selected psychological works, 554 (2009)

14. L.I. Badanina, Diagnostics and development of cognitive processes. Workshop on general psychology, 264 (2012)

15. D.E. Berline, Curiosity and information search, Questions of psychology, 3, 54-60 (2009)

16. L.N. Prokhorova, Organization of experimental activity of preschoolers, 267 (2012)

17. K.M. Ramonova, Features and ways of their development of curiosity in preschool children, 257 (2009)

18. T.I. Shamova, The problem of cognitive interest in pedagogy, 351 (2009)

19. V.S. Yurkevich, Development of the initial levels of cognitive needs in children, Questions of psychology, 2, 83-92 (2009)

20. Adolph Diesterweg, His educational ideal and his failure Wehebrink, ChristianWilhelm, 210 (2017)

21. A.G. Ruzskaya, Development of communication of preschoolers with peers, 215 (2015)

22. A.B. Zaporozhets, Y.Z. Neverovich, The development of social emotions in preschool children, 176 (2006)

23. C.B. Peterina, Education of a culture of behavior in preschool children, 96 (1986)

24. M.I. Enikeev, Psychological encyclopedic dictionary, 560 (2010)

25. Yu.V. Polyakevich, G.N. Osinina, Formation of communication skills in children 3-7 years old: models of complex lessons, 159 (2011) 